\title{
PENGUNGKAPAN AKTIVITAS GREEN SUPPLY CHAIN MANAGEMENT PADA PERUSAHAAN KATEGORI EMAS PROPER 2013 - 2014
}

\author{
Temy Setiawan \\ Universitas Bunda Mulia \\ tsetiawan@bundamulia.ac.id
}

\begin{abstract}
The problems with the environment which has grabbed the public attention is the main reason for the development of green supply chain management.Companies need to take parts in this continuous development. One efforts which has been done is to disclose of environmental activities in sustainable reporting.This research is aimed to explore the information of companies' activity in relation to environmental issues. This research classifies the criteria of green supply chain management into 4 categories : green purchasing; eco design; reverse logistic and regulator.This is a qualitative research. The researcher conducts an analysis on 6 companies listed in 2013 PROPER with gold predicate.This research finds that the most common activities conducted by the companies in taking their responsibilities to the environment is legislation and regulator pressure and $\mathrm{PT}$. Medco E\&P Indonesia which has devoted most of their activities to environmental issues. All of the company has achieved the environmental performance and few companies have increasing net income.There is a very limited research focused on companies activities as related to green supply chain management. This research will explain the specific environmental activities in which companies are focused on in responding the green supply chain management.
\end{abstract}

Keywords :green supply chain management; green purchasing; eco design; reverse logistic and regulator.

\section{Pendahuluan}

Polemik perhatian terhadap isu lingkungan saat ini menimbulkan pro dan kontra bagi sebagian besar organisasi bisnis (perusahaan). Perusahaan menganggap bahwa perhatian terhadap lingkungan sudah merupakan suatu kewajiban.

Perusahaan dipaksakan untuk melakukan tindakan yang berupaya untuk melindungi atau membatasi eksploitasi terhadap alam (Bourdeau, 2004). Begitu pula tekanan dari stakeholder semakin besar. Hal ini menyebabkan perusahaan berupaya 
sebaik mungkin dalam

Zvezdov,2012; $\quad$ Porter dan

memperhatikan masalah lingkungan

Kramer,2002). Radyati (2014)

(Gunawan,2010; Porter dan

menjelaskan bahwa perhatian

Kramer,2006). Penyelesaian

terhadap lingkungan merupakan

terhadap masalah lingkungan

elevator bisnis dalam memperoleh

merupakan isu yang menjadikan

laba jangka panjang.Hal ini

keunggulan kompetitif bagi

perusahaan.Masyarakat dan

disebabkan pada aspek efisiensi

karyawan sudah memiliki kepekaan

terhadap kesadaran lingkungan

sehingga perusahaan yang disebut

sebagai perusahaan hijau (green

company) cukup mendapat apresiasi

dari pemangku kepentingan. (Hansen

dan Mowen 2015; Lako,2014).

Perusahaan yang memperhatikan isu

lingkungan cenderung dapat meningkatkan kinerja keuangan jangka panjang melalui peningkatkan citra perusahaan kepada pemangku kepentingan (Butler et al,2011, Radyati,2014; Hasan,2009; Gunawan,2015a).

Perusahaan tidak lagi dihadapkan pada peningkatan kinerja yang diukur dari laba saja namun memperhatikan aspek lingkungan yang merupakan salah satu bagian dari konseptriple bottom line yang mencakup :profit, people, planet(Quinn dan Baltes,2007; Elkington,1997; $\quad$ Dhiman,2008; biaya, kepatuhan terhadap peraturan yang berlaku, peningkatan citra dan kepercayaan para pemangku kepentingan.

Salah satu upaya dalam pencapaian kinerja dalam kerangka triple bottom line adalah penerapan green supply chain management (GSCM).Sektor industri sebagai pelaku utama dalam permasalahan lingkungan hendaknya menyadari pentingnya penggunaan teknologi yang ramah lingkungan dalam menjalankan proses produksinya guna meminimalkan waste dan mengurangi dampak negatif bagi lingkungan sekitar. Supply Chain adalah jaringan seluruh organisasi mulai dari pemasok sampai ke pengguna akhir, yang didalamnya terdapat aliran dan transformasi material, informasi dan uang. Setiap aktivitas yang dilakukan oleh para pelaku rantai pasok tersebut berpeluang untuk menciptakan 
polusi, waste, dan bahan-bahan berbahaya bagi lingkungan. (Fortuna, et al., 2014)

Semua tahapan dalam supply chain mempengaruhi beban lingkungan mulai dari ekstraksi sumber daya, manufaktur, distribusi, penggunaan produk, pembuangan limbah dan kegiatan lainnya. Resiko terkait dengan lingkungan antara lain: penggunaan air dan energi yang berlebihan tanpa konservasi, penggunaan bahan kimia berbahaya, polusi, pencemaran dan lain sebagainya. Berbagai ide bermunculan dari peneliti dan akademisi untuk mengintegrasikan aspek lingkungan ke dalam pengelolaan proses bisnis sehingga tercipta konsep green supply chain management. (Saputra,et al. 2012).

GSCM bertujuan untuk mengeliminasi atau meminimasi waste (energi, gas emisi, bahan kimia berbahaya, limbah) di sepanjang jaringan rantai pasok. Komponens aktivitas GSCM terdiri dari green procurement (pengadaan ramah lingkungan), green manufacturing (manufaktur ramah lingkungan), green distribution (distribusi ramah lingkungan), dan reverse logistic(Ninlawan et al., 2010; Fortuna, et al.,2014).

Aktivitas GSCM ini pun memperoleh perhatian dari Program Penilaian Peringkat Kinerja Perusahaan (PROPER) yang merupakan agenda dari kementrian lingkungan hidup. Dalam PROPER, perusahaan yang dinilai akan diberikan peringkat berdasarkan kriteria penilaian tertentu. Lima peringkat yang dimaksud adalah : emas, hijau, biru, merah dan hitam. Pengungkapan aktivitas GSCM perusahaan dapat diamati dalam laporan tahunan ataupun laporan keberlanjutan yang dipublikasikan perusahaan pada akhir periode (Gunawan 2015b; Suttipun dan Stanton,2014).

Tujuan dari penelitian ini adalah untuk mengeksplorasi aktivitas perusahaan yang terdaftar dalam PROPER kategori emas berdasarkan kriteria GSCM. Kontribusi penelitian ini adalah memberikan informasi kepada pembaca mengenai aktifitas apa saja di dalam kriteria GSCM dan 
memberikan motivasi kepada perusahaan yang beroperasi di Indonesia untuk memperoleh kriteria emas dalam PROPER.

\section{Tinjauan Literatur}

\subsection{Teori Legitimasi}

Legitimasi merupakan keadaan psikologis keberpihakan orang dan kelompok orang yang sangat peka terhadap gejala lingkungan sekitarnya baik fisik maupun non fisik.O'Donovan (2000) berpendapat legitimasi organisasi dapat dilihat sebagai sesuatu yang diberikan masyarakat kepada perusahaan dan sesuatu yang diinginkan atau dicari perusahaan dari masyarakat.Dengan demikian, legitimasi merupakan manfaat atau sumber daya potensial bagi perusahaan untuk bertahan hidup (going concern) karena terjadi hubungan timbal balik antar dua entitas yaitu perusahaan dan lingkungan.

Legitimasi juga merupakan suatu padangan atau persepsi atas tindakan suatu entitas yang sesuai dengan sistem norma, nilai, kepercayaan yang dibangun secara sosial. Teori legitimasi fokus pada berbagai strategi manajer dalam perusahaan yang memilih untuk mempertahankan standar yang tinggi atas legitimasinya (Deegan,2002a).

Legitimasi mengalami pergeseran bersamaan dengan perubahan dan perkembangan lingkungan dan masyarakat di mana perusahaan berada. Perubahan nilai dan norma sosial dalam masyarakat sebagai konsekuensi perkembangan peradaban manusia, juga menjadi motivator perubahan atau pergerseran legitimasi.

Lindblom (1994) dalam O’ Donovan (2002) :

"Legitimacy is dynamic in that the relevant public continuously evaluate corporate output, method, and goals againstan ever-evolving expectation. The legitimacy gap will fluctuate without any changes in action on the part of the corporation. Indeed, as expectation of the relevant publics change the corporation must make changes or the legitimacy gap will grow as the level of conflict increases and the levels of positive and passive support decreases." 
Legitimasi mengalami pergeseran sejalan dengan pergeseran masyarakat dan lingkungan yang disebut sebagai legitimacy gap.Pergeseran ini dapat terjadi sendirinya tanpa ada tindakan apapun oleh perusahaan karena sifat dari legitimasi yang dinamis.Perusahaan harus dapat menyesuaikan perubahan tersebut baik melalui produk, metode dan tujuan yang dijalankan. Apabila penyesuaian terhadap legitimacy gap tidak dilakukan, maka akan menimbulkan konflik.

Dengan kata lain, legitimacy gap dapat dijelaskan sebagai perbedaan antara ekpektasi yang diharapkan dari stakeholder terhadap aktivitas entitas dengan kondisi aktual atas aktivitas entitas di dalam masyarakat. Oleh karena itu, entitas berupaya untuk mempekecil legitimacy gap yang ada namun dengan adanya tantangan kondisi eksternal yang tidak dapat dikendalikan.

Deegan (2002b) menyatakan legitimasi dapat diperoleh manakala terdapat kesesuaian antara keberadaan perusahaan yang tidak mengganggu atau sesuai (congruent) dengan eksistensi sistem nilai yang ada dalam masyarakat dan lingkungan.Ketika terjadi pergeseran yang menuju ketidaksesuaian, maka pada saat itu legitimasi perusahaan dapat terancam.

\subsection{Stakeholder Theory}

Stakeholdertheory mengatakan bahwa perusahaan bukanlah entitas yang hanya beroperasi untuk kepentingannya sendiri namun harus memberikan manfaat bagi stakeholder (pemegang saham, kreditor, konsumen, supplier, pemerintah, masyarakat, analis dan pihak lain). Dengan demikian, keberadaan suatu perusahaan sangat dipengaruhi oleh dukungan yang diberikan oleh stakeholder kepada perusahaan tersebut.

Gray et al. (1994) dalam Hanggarwati dan Mutmainah (2013) mengatakan bahwa kelangsungan hidup perusahaan tergantung pada dukungan stakeholders dan dukungan tersebut harus dicari sehingga aktivitas perusahaan adalah untuk mencari dukungan tersebut(Hanggarwati dan Mutmainah, 2013). 
Stakeholder theory memperhatikan keseluruhan pihak yang mempunyai kepentingan terhadap perusahaan. Stakeholder perusahaan memiliki ekspektasi masing-masing terhadap perusahaan. Manajemen akan berusaha untuk mengelola dan mencapai harapan stakeholder dengan penyampaian aktivitasaktivitas lingkungan dan sosial (Kusumaningtias, 2013).

\subsection{Akuntansi Lingkungan}

Akuntansi lingkungan disusun untuk mengidentifikasi, mengukur dan mengkomunikasikan aktivitas perusahaan berdasarkan biaya konservasi lingkungan (environmental conservation cost) atau manfaat ekonomi (economic benefit) dari aktivitas konservasi atas lingkungan, kinerja keuangan perusahaan yang dinyatakan secara moneter dan kinerja lingkungan yang dinyatakan secara fisik.

Stechemesser dan Guenther (2012) menjelaskan bahwa akuntansi lingkungan berdasarkan pemangku kepentingannya dapat dibedakan atas akuntansi keuangan lingkungan (environmental financial accounting) dan akuntansi manajemen lingkungan (environmental management accounting) (Stechemesser dan Guenther,2012). Beyene (2015)mendefinisikan akuntansi lingkungan sebagai :

"Green accounting is one of the contemporary concepts in accounting that support the green movement in the company or organization by recognizing, quantifying, measuring and disclosing the contribution of the environment to the business process".

Berdasarkan definisi green accounting di atas maka bisa dijelaskan bahwa green accounting merupakan akuntansi yang di dalamnyamengidentifikasi,

mengukur, menilai, dan mengungkapkanbiaya-biaya terkait dengan aktivitasperusahaan yang berhubungan dengan lingkungan.

\subsection{Menuju Green Supply Chain Management}

Ketika suatu perusahaan berusaha untuk mencapai keberlanjutan (sustainability) dalam aspek lingkungan, manajemen harus 
memperluas usaha mereka untuk meningkatkan praktik yang berhubungan dengan lingkungan di sepanjang supply chain.Semua faktor yang mempengaruhi elemen khusus dalam suatu rantai akan diperpanjang ke rantai lainnya. Berdasarkan pendapat-pendapat tersebut dapat disimpulkan bahwa pada green supply chain management, penilaian proses internal (midstream) perusahaan harus digabungkan dengan proses eksternal (upstream dan midstream) yang melibatkan pemasok (supplier), agen penyalur barang (distributor) dan pelanggan (customer). Revolusi kualitas pada akhir tahun 1980 dan revolusi supply chain pada awal tahun 1990 telah memperjelas bahwa praktik terbaik memerlukan integrasikan pengelolaan lingkungan dengan aktivitas operasi yang dilakukan secara kontinu.Selain itu, permintaaan pasar global dan tekanan pemerintah mendorong bisnis menjadi lebih sustainable. Hal ini mendorong banyak perusahaan untuk mengintegrasikan aspek ramah lingkungan (green) ke dalam supply chain. (Saputra,et al., 2012).
Gambar 2.1

\section{Supply Chain and Sustainbility}

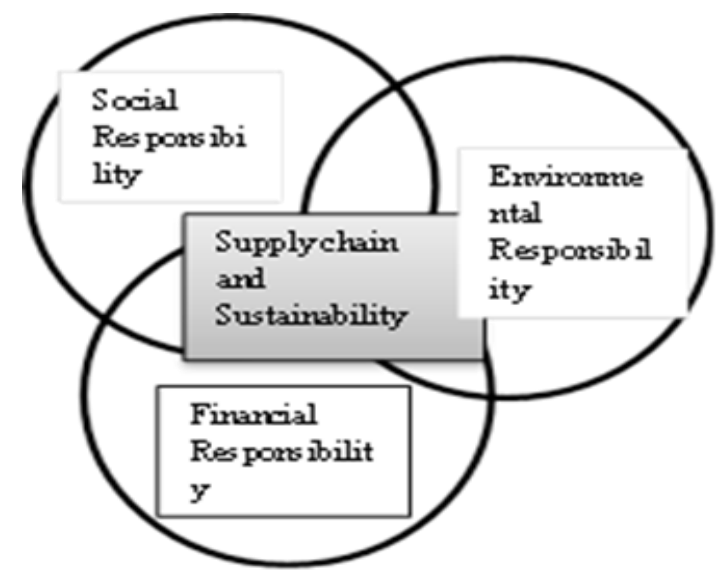

Gambar 2.1 menunjukan, rantai pasokan berkelanjutan (green supply chain) memiliki tiga elemen. Pertama, financial responsibility membahas kebutuhan keuangan kepada pemegang saham (shareholders),karyawan (employee), pelanggan (customers), rekan bisnis (business partners), intitusi keuangan (financial institutions), dan pemasok (supplier). Rantai pasokan (supply chain), bagian dari itu, mendukung tanggung jawab keuangan (financial responsibility) yang dipengaruhi kontribusi elemen return on assets, karena rantai pasokan (supply chain) proses dasarnya terkait, perbaikan apapun untuk memproses atau manajemen 
mereka, seperti yang dijelaskan di bagian 1 dan 2 dari teks, meningkatkan kesejahteraan keuangan perusahaan dan meningkatkan itu kemungkinan bertahan di dunia yang kompetitif.

Kedua, environmental responsibility membahas kebutuhan ekologi planet ini dan kepengurusan perusahaan dari sumber daya alam yang digunakan dalam produksi jasa dan produk.tujuannya adalah untuk meninggalkan sekecil jejak lingkungan mungkin sehingga generasi mendatang memanfaatkan sumber daya yang melimpah. Rancangan dan integrasi supply chain dapat berperan utama dalam melestarikan sumber. Kita harus memeriksa bagaimana supply chain dapat di rancang untuk memproduksi produk dan kemudian memproses kembali produk dan akhirnya menghasilkan nilai dalam bentuk produk ulang atau bahan daur ulang. Kita harus juga memeriksa bagaimana supply chain dapat merencanakan rute untuk mengurangi energi yang dikonsumsi dalam menyampaikan bahan atau produk ke pelanggan.

Terakhir, social responsibillity membahas moral, etika,dan harapan filantropi bahwa masyarakat memiliki organisasi. Sementara tanggung jawab ini mencakup berbagai kegiatan supply chain dapat digunakan untuk memenuhi harapan tersebut (Krajewski et al.,2013).

\section{Metode Penelitian}

Penelitian ini merupakan penelitian kualitatif deskriptif dengan populasi adalah perusahaan yang masuk dalam kriteria emas pada penilaian PROPER 2014 yaitu : PT Medco E\&P Indonesia; PT Bukit Asam; PT Pertamina Geothermal Energy; PT Holcim Indonesia; PT Bio Farma; PT Pertamina. Teknik analisis yang digunakan dalam penelitian ini adalah sebagai berikut :

1) Menggumpulkan Annual Report dan Sustainability Report.

2) Mengidentifikasikan aktivitas perusahaan terhadap lingkungan.

3) Mengklasifikasikan aktivitas tersebut terhadap indikator dari kegiatan Green Supply Chain 
Management dengan kinerja lingkungan dan ekonomi.

4) Melakukan

pembahasan perusahaan terhadap masingmasing sub dari indikator.

5) Menganalisis perusahaan yang terdapat dalam PROPER periode 2014.

\section{Hasil Penelitian}

dan

\section{Pembahasan}

Data yang peneliti gunakan adalah Sustainability Report dan Annual Report yang terdapat pada perusahaan yang terdaftar dalam Penilaian Peringkat Kinerja Perusahaan dalam Pengelolaan Lingkungan Hidup (PROPER) Periode 2014 berikut adalah hasil analisis penyajian data peneliti. Pada tabel 4.1 adalah perusahaan yang mendapatkan peringkat emas dalam mengikuti PROPER dalam hal tersebut dapat dilihat bahwa perusahaan yang melakukan aktivitas Green Supply Chain Management yang paling banyak dilakukan oleh

PT. Medco E\&P Indonesia yang berjumlah 14 sedangkan perusahaan yang paling sedikit yaitu dilakukan oleh PT. Pertamina Geothermal
Energy dan PT. Pertamina (Persero) yang berjumlah 7 .

Pada tabel 4.2, menunjukkan beberapa aktivitas-aktivitas yang dilakukan oleh perusahaanperusahaan yang mendapatkan peringkat emas dalam mengikuti PROPER pada tahun 2014. Berikut ini adalah hasil analisis peneliti pada aktivitas yang dijalankan oleh perusahaan dalam penerapan green supply chain management (GSCM.).

\section{PT. Medco E\&P Indonesia \\ - Green Purchasing}

Dalam kegiatan tersebut, Medco melakukan pemilihan atau seleksi pemasok yang akan menjadi partner Medco. Medco membuat standar perilaku yang dianut oleh lingkungan kerja Perseroan, sesuai dengan nilainilai perusahaan termasuk dikomunikasikan oleh pemasok serta dalam menjalin hubungan dengan para pemasok maka Medco Energi menajalankan kode etik Kode Etik ini menjabarkan standar perilaku yang dianut di lingkungan kerja Perusahaan, sesuai dengan nilai-nilai perusahaan yaitu profesional, etis, terbuka dan inovatif. Medco juga berencana untuk menekan intensitas 
energi melalui serangkaian Program Inisiatif Hijau berupa utilisasi gas ikutan, modifikasi desain peralatan, mengatur komposisi campuran bahan kimia dalam proses produksi, cogeneration dan juga penggunaan lampu LED serta tenaga surya pada sebagian pendukung operasinya.

\section{- $\quad$ Terkait Produk Eco-Desain}

Medco dalam mengelola produknya seperti limbah organik yang dihasilkan. Medco Energi mengolah sampah domestik organik menjadi kompos, untuk kemudian digunakan sebagai pupuk beras organik, tanaman obat dan kebun sayur. Sebagian besar limbah organik dari aset telah dibuat kompos melalui program lingkungan hidup terpadu Medco Energi, yang melibatkan masyarakat setempat yang tinggal di sekitar lingkungan aset Medco Energi. Dalam penilaian terhadap siklus kehidupan maka Medco Energi komitmen dalam mendorong pembangunan berkelanjutan melalui pertumbuhan ekonomi berkelanjutan, keseimbangan ekologi dan pertumbuhan sosial yaitu Indonesia Business Council for Sustainable Development. Perusahaan juga melaksanakan sistem daur ulang dengan mendirikan bank sampahdi Sumatra Selatan dan Karang Taruna Desa Lais di Kabupaten Musi Banyuasin (KATALIS) untuk mendistribusikan limbah anorganik yang dihasilkan seperti plastik untuk didaur ulang menjadi biji plastik dan suvenir dengan tujuan untuk mengurangi limbah kemasan dan limbah B3.

\section{- Reverse Logistic}

Medco Energi dalam menerapkan green supply chain management (gscm) tidak melakukan kegiatan reverse logistic yang berhubungan langsung dengan pemasok dan pelanggan dalam hal pengumpulan kemasan produk karena Medco merupakan perusahaan dibidang Migas.

\section{- $\quad$ Legalisation and Regulator}

Medco dalam melakukan kebijakan pemerintah juga mendapatkan ISO 14001 (Sistem Manajemen Lingkungan) serta ikut dalam PROPER yang diadakan oleh pemerintah. Medco juga mendapatkan pengakuan dari lembaga keuangan dunia seperti International Finance Corporation (IFC), sehingga Medco lebih leluasa untuk mendapatkan modal dan 
pendanaan dari pasar uang nasional maupun internasional. Seperti diketahui, dewasa ini dunia perbankan dan pasar modal semakin mensyaratkan perilaku usaha ramah lingkungan bagi suatu perusahaan yang mencari dukungan modal demi keberlanjutan usahanya.

\section{PT. Bukit Asam, Tbk}

\section{Green Purchasing}

PTBA melakukan seleksi pemasok dengan menerapkan Sistem Manajemen dan Keselamatan Kerja (SMK3) yaitu sebuah hubungan timbal balik jangka panjang yang saling menunjang selain itu, dalam menjalin kerjasama dengan pemasok, kriteria menghargai hak asasi manusia dan masyarakat lokal juga menjadi pertimbangan. Dengan kriteria itu, maka selama periode pelaporan, tidak ada dampak negatif dan faktual yang terjadi berkaitan dengan hak asasi manusia dan masyarakat lokal dalam rantai pasokan. Dalam memperhatikan aspek lingkungan PTBA membeli bahan material yang ramah lingkungan dengan kandungan/kadar abu yang rendah, kadar sulfur rendah dan ramah lingkungan.

\section{Terkait Produk Eco-Desain}

PTBA menerapkan prinsip green mining adalah mengedepankan pelestarian lingkungan dan kepentingan masyarakat dalam kegiatan produksi, termasuk dalam mengatasi hambatan produksi dan menyiapkan rencana produksi masa berikutnya. Lingkungan menjadi bagian yang integral dalam seluruh siklus penambangan di mana aktivitas menambang adalah bagian dari rencana pasca tambang. Upaya pencegahan pencemaran dan pengurangan beban lingkungan terhadap air permukaan dilakukan PTBA dengan membangun sistem pengolah air tertutup. Dengan sistem ini, setiap timbulan air larian dari tambang disalurkanke kolam-kolam pengendapan lumpur sebagai bagian dari kegiatan reklamasi tambang untuk diolah. Semua air yang dibuang dari areal penambangan diuji setiap bulan untuk memastikan kualitasnya agar sesuai dengan baku mutu kualitas air yang berlaku serta PTBA melaksanakan AMDAL (Analisis Mengenai Dampak Lingkungan) bertujuan untuk untuk mengidentifikasi dampak lingkungan 
yang dapat terjadi dan menyusun rencana untuk memantau dan mengelola dampak tersebut. PTBA mengikuti hierarki produksi bersih untuk mengurangi limbah, yaitu dengan reduce (mengurangi), reuse (menggunakan kembali), dan recycle (mendaur ulang). Dalam menggurangi bahan berbahaya PTBA membuat kebijakan sumber daya mengenai pengurangan dan pemanfaatan limbah B3 dan limbah padat non B3. Pelaksanaan program pengelolaan dan pemanfaatan

limbah B3 dilakukan oleh sumber daya manusia yang kompeten dan tersertifikasi dengan ketersediaan dana yang memadai.

\section{Reverse Logistic}

Dalam pelaksanaan kegiatan ini, PTBA tidak melakukan aktivitas yang terkait dengan reverse logistic dalam mengumpulkan dan mengembalikan produk ke supplier ataupun pelanggan.

\section{Legalisation and Regulator}

Terhadap standar lingkungan PTBA mengadakan penerapan standar eksternal yaitu Perseroan merujuk pada sejumlah standar pelaksanaan yang sudah terakreditasi, yakni Sistem Manajemen Mutu (SMM)
ISO 9001: 2008; Sistem Manajemen Lingkungan (SML) ISO 14001: 2004, dan Sistem Manajemen Kesehatan dan Kecelakaan Kerja (SMK3) OHSAS 18001: 2007. Semua standar itu terintegrasi dalam satu sistem, yakni Sistem Manajemen Bukit Asam (SMBA). PTBA juga mengikuti Program Penilaian Peringkat Kinerja Perusahaan (PROPER) yang diselenggarakan oleh Propinsi Sumatera Selatan (PROPER Daerah) dan nasional (PROPER

Kementerian Lingkungan Hidup).

\section{PT. Pertamina Geothermal Energy}

\section{- $\quad$ Green Purchasing}

PGE melakukan seleksi terhadap pemasok dengan menerapkan kode etik yang sudah menjadi kebijakan PGE yaitubentuk kesungguhan dari perusahaan untuk mengimplementasikan tata kelola perusahaan yang baik dalam setiap aktivitas operasional perusahaan. Seluruh Manajemen dan Pekerja wajib memahami kode etik perusahaan sebagai dasar penerapan perilaku yang mengatur hubungan antara pekerja dengan perusahaan, 
sesama pekerja, konsumen, pemasok, pemegang saham, pemangku kepentingan, pemerintah dan masyarakat salah satunya dalam bentuk lingkungan kerja.

\section{- $\quad$ Terkait Produk Eco-Desain}

PGE menggunakan energi ramah lingkungan seperti energi panas bumi merupakan sumber energi yang ramah lingkungan dan berkelanjutan. Hal ini tercermin dari emisi gas rumah kaca panas bumi yang sangat kecil dibanding energi lainnya, yaitu; Sulfur Dioksida (SO2), Nitrogen Dioksida (NO2), dan Karbon Dioksida (CO2). Lebih lanjut, manajemen reservoir yang baik dapat menjaga keberlanjutan pasokan energi panas bumi. Pemerintah Indonesia juga mendukung upaya pemanfaatan potensi energi panas bumi Indonesia yang besar sebagai bagian dari Kebijakan Energi Nasional dan PGE selalu berkomitmen untuk menjaga kelestarian lingkungan yang ada.

\section{- $\quad$ Reverse Logistic}

PGE tidak melaksanakan reverse logistic dalam salah satu proksi yang ada dalam green supply chain management (gscm).

\section{Legalisation and Regulator}

Sebagai salah satu perusahaan publik maka PGE Menerapkan aspek teknologi K3LL secara tepat guna meliputi eksplorasi, eksploitasi, dan produksi panas bumi yang aman sesuai standar yang berlaku, serta ramah lingkungan. PGE juga mengikuti PROPER dalam penilaian kinerja lingkungan serta UndangUndang Nomor 40 Tahun 2007 berisi tentang Informasi berkala yang diterbitkan oleh Perusahaan antara lain Laporan Tahunan (Annual Report), Laporan Keuangan yang telah diaudit (Audited Financial Report), dan Laporan Keberlanjutan (Sustainability Report).

\section{PT. Holcim Indonesia, Tbk Green Purchasing}

HIL melakukan penyeleksian terhadap pemasok dengan melakukan kegiatan Program pendayagunaan lahan perkebunan kayu putih dengan tujuan untuk pelestarian flora dan fauna daerah dan perlindungan wilayah pesisir serta memberikan pendapatan tambahan untuk masyarakat sekitar.

Jadi, HIL memberikan pengarahan cara berkebun yang ramah lingkungan sehingga tidak merusak 
lingkungan sekitar. HIL juga berhasil mendapatkan akreditasi Singapore Environmental Council (SEC) untuk kantor pusat. Aspek yang dinilai untuk akreditasi sebagai kantor ramah lingkungan, salah satu yang pertama di Indonesia, adalah konservasi energi dan air, manajemen efektif limbah dan daur ulang limbah.

\section{Terkait produk Eco-Desain}

HCI dalam menghitung dampak lingkungan yang akan dihasilkan sebagai penilaian siklus kehidupan menggunakan perhitungan True Value. Cara perhitungannya yaitu khususnya laba ditahan dari hasil usaha, ditambah dengan nilai ekonomi yang dihasilkan melalui program CSR kemudian dikurangi biaya kesehatan yang dibukukan sebagai imbas kegiatan operasional. Hasil yang diperoleh selanjutnya ditambah dengan nila sumber daya yang dapat dimanfaatkan kembali, misalnya air yang ditampung, atau bahan bakar dan bahan baku alternatif yang dipakai, dan lahan hasil rehabilitasi yang ada di sekitar lokasi tambang, misalnya. Angka tersebut kemudian dikurangi lagi dengan biaya pengadaan sumber daya, lahan dan air yang dipakai untuk menghasilkan semen. Hasil akhirnya adalah TrueValue. HCI juga menerapkan daur ulang bahan baku dan komponen mineral untuk mengurangi konsumsi gamping. HCI juga menerapkan eco-desain yang mendapatkan seterfikat green label sebagai semen serba guna Holcim.

\section{- $\quad$ Reverse Logistic}

HCI tidak melakukan aktivitas ini dalam pengumpulan dan pengembalian produk atau kemasan ke supplier dan pelanggan.

\section{galisation and Regulator}

HIL menetapkan standar sesuai dengan Singapore Environmental Council (SEC) yang standarnya diakui negara-negara di dunia, dan didasarkan pada metode siklus hidup mulai dari bahan baku, proses produksi hingga pengiriman ke pelanggan, dan kemudian daur ulang hingga proses pembuangan produk tanpa mengabaikan kelestarian lingkungan. HIL juga mengikuti program PROPER yang diadakan oleh pemerintah serta mematuhi kebijakan tentang peraturan yang berlaku untuk perusahaan terbuka, persyaratan hukum, standar keselamatan kerja dan standar 
akuntansi, baik internasional maupun nasional, serta peraturan ketenagakerjaan dan lingkungan hidup di daerah.

\section{PT. Bio Farma (Persero)}

\section{- Green Purchasing}

PT. Bio Farma menerapkan beberapa kebijakan sebagai green company salah satunya adalah green process yaitu seluruh proses bisnis perusahaan dari pemilihan bahan baku (melalui seleksi vendor-sadar lingkungan). Salah satu untuk menerapkan ramah lingkungan Bio Farma menjalankan strategi human capital salah satunya green process/product.

\section{- Terkait Produk Eco-Desain}

Bio Farma menerapkan konsep waste management dimulai dari pemisahan sampah, penyimpanan dan pengelolaan selanjutnya dari kompos sampah organik dan daur ulang non-organik buang untuk mengurangi beban tempat pembuangan sampah. Bio Farma juga bertujuan untuk menjaga kelestarian lingkungan dengan mengadakan program Silvofishery dan konservasi program manggrove.
Bio Farma menerapkan konservasi bakau program di wilayah pesisir Karangsong, Indramayu Kabupaten, Jawa Barat. Program ini telah dilakukan sejak 2012, yang melibatkan penanaman 12.300 bakau pohon. Pada bulan Februari 2014, Bio Farma menginstal daur ulang air memompa dengan panel surya yang digunakan untuk mentransfer air baku dari recycle water plant ke tangki. Untuk mengirim air, pompa mengkonsumsi daya $2,4 \mathrm{~kW}$ untuk sekitar 10 jam sehari berasal dari panel surya. Penggunaan panel surya untuk pompa daur ulang air mengakibatkan penurunan konsumsi listrik dari PLN atau dari genset dengan 5,76 MWh per tahun. Bio Farma percaya bahwa vaksin berkualitas tinggi yang ramah lingkungan hanya dapat terwujud melalui produksi kondusif dan ramah lingkungan kegiatan, dan pelaksanaan lingkungan manajemen secara komprehensif, mulai dari tahap perencanaan, pelaksanaan, pemantauan, review, dan perbaikan terus-menerus, dengan eco-efficient prinsip produksi. Inovasi terbaru Bio Farma, yaitu Pentabio vaksin, yang terdiri dari 5 vaksin yang berbeda 
(Difteri, Tetanus, Pertusis, HB dan HiB vaksin) menggabungkan dalam satu produk tunggal, sehingga memaksimalkan efisiensi dalam berbagai aspek termasuk listrik dan konsumsi air selama proses produksi terutama pengurangan kemasan dan limbah. Inovasi Pentabio adalah salah satu indikator dari Bio keberhasilan Farma dalam penelitian produk. Inovasi adalah dimplementasikan dalam proses vaksin mengisi, sehingga yang D, T, P, Hib, dan vaksin HB dapat diintegrasikan dalam satu produk tunggal. Tujuan inovasi adalah untuk meningkatkan Nilai produk di mana konsumen dapat memperoleh 5 vaksin yang berbeda dalam satu produk tunggal pada lebih murah harga, dan juga untuk mengurangi jumlah kunjungan ke fasilitas kesehatan. Di sisi lain, hal ini dapat mengurangi penggunaan bahan yang berbahaya.

\section{- Reverse Logistic}

Dalam penerapan aktivitas ini, Bio Farma tidak mengadakan aktivitas yang sehubungan dengan reverse logistic

\section{- Legalisation and Regulator}

Untuk mendukung kegiatan Perusahaan yang menjunjung semangat Go Green Industry, divisi teknologi informasi memiliki aplikasi yang diimplementasikan yang dapat mengurangi penggunaan kertas dan mengakibatkan paperless bisnis di semua kegiatan administratif internal. Bio Farma melakukan Corporate Social Responsibility (CSR) berdasarkan ISO 26000: 2010 pedoman standar untuk Tanggung Jawab Sosial. Sejak 1890 ketika Perusahaan pertama kali didirikan sampai sekarang di tahun 124-nya, Bio Farma memiliki keterampilan dan pengalaman dalam mengembangkan dan mengelola virus dan bakteri, lingkungan, air, udara, rantai dingin dan sistem distribusi. Bio Farma juga mengikuti PROPER yang diadakan oleh pemerintah serta menjalankan kebijakan pemerintah mengenai lingkungan sesuai dengan Peraturan Nomor 32/2009 tentang Perlindungan dan Pengelolaan Lingkungan. Bio Farma berkomitmen untuk menjadi hijau dan berkelanjutan korporasi dengan mengoperasikan pro-lingkungan dan pro-community bisnis. Bio Farma memiliki kebijakan ketat pada 
memanfaatkan energi dan sumber daya alam secara efisien dan efektif.

\section{PT. Pertamina (Persero)}

\section{Green Purchasing}

Pertamina menerapkan perangkat Contractor Safety Management System (CSMS), yang diberlakukan sejak tahun 2010. CSMS merupakan bagian dari mitigasi risiko $\mathrm{K} 3$ sesuai dengan peraturan SKK Migas. Pertamina bertujuan juga untuk menyeleksi pemasok melalui CSMS adanya pemasok yang menjual seperti freon yang ramah lingkungan serta Pertamina juga menggunakan produk EXDO-4 merupakan produk rubber

processing oil (RPO) atau minyak yang digunakan sebagai bahan baku pembuat ban. EXDO-4 bersifat ramah lingkungan dan nonkarsinogen atau tidak menimbulkan potensi kanker.

\section{Terkait Produk Eco-Desain}

Pertamina melakukan Full

Assessment International Safety

Rating System (ISRS) sudah dilakukan oleh DNV di RU V dari tanggal 20-24 Oktober 2014. Assessment dilakukan melalui 15 proses, meliputi aspek Quality,
People Safety, Process Safety dan Process Business. Melalui penerapan ISRS, proses bisnis di RU V dapat dijamin tingkat pemenuhannya, yaitu mencakup Sistem Manajemen Mutu, K3, dan Lingkungan, yang bersertifikasi Internasional. Dari hasil assessment, RU V berhasil mendapat score 5, yaitu target yang semestinya baru diterapkan di 2017.

\section{Reverse Logistic}

Pertamina tidak melakukan aktivitas dari reverse logistic karena Pertamina merupakan perusahaan minyak nasional yang kemungkinan kecil dapat melakukan aktivitas ini.

\section{Legalisation and Regulator}

Pertamina aktif mendukung program pemerintah dalam Millenium Development Goals (MDGs) melalui program inisiatif-inisiatif CSR, program kemitraan dan bina lingkungan serta kegiatan yang dilakukan oleh Pertamina Foundation. Program CSR

Pertamina bertemakan Pertamina Sobat Bumi dengan mengangkat empat pilar unggulan yaitu Pertamina Cerdas, Pertamina Sehat, Pertamina Hijau dan Pertamina Berdikari. Pertamina menerapkan ISO 26000 dan melakukan penilaian 
mengikuti PROPER yang diadakan oleh Pemerintah. Untuk mendukung kebijakan Pemerintah maka Pertamina melakukan Program Kemitraan dan Bina Lingkungan (PKBL) seperti kegiatan usaha para mitra binaan juga menyediakan lapangan pekerjaan bagi warga setempat, sehingga masyarakat bisa memperoleh penghasilan. Dengan demikian masyarakat dapat merasakan manfaat tidak langsung dari keberadaan unit operasi/unit bisnis Perseroan.

\section{Simpulan}

Isu lingkungan yang semakin menyedot masyarakat luas tidak dapat dielakan akan mempengaruhi proses bisnis. Perusahaan selaku produsen harus memperhatikan proses rantai pasokan yang dimilikinya. Rantai pasokan diharapakan memperhatikan lingkungan yang dikenal dengan green supply chain management (GSCM). Upaya ini dilakukan agar kelestarian lingkungan dapat tetap terjaga meskipun perusahaan memaksimalkan potensi untuk memperoleh laba.Hal ini sejalan dengan konsep triple bottom line.
GSCM menekankan proses rantai pasokan ke dalam 4 aktivitas :green purchasing, eco design, reverse logistic and legislation and regulator. Dari 6 perusahaan yang terdaftar pada PROPER kategori emas 2014, seluruh perusahaan melakukan dan mengungkapkan 3 aktivitas disebutkan di atas kecuali aktivitas reverse logistic yaitu menerima kembali kemasan dari pelanggan atau mengembalikan kemasan atau sampah produksi kepada supplier dalam laporan keberlanjutan dan atau laporan tahunan mereka. Seluruh perusahaan tersebut mencapai kinerja lingkungan yang baik dan beberapa dari mereka memperoleh peningkatkan kinerja ekonomi yang diukur dengan peningkatan laba.

Saran bagi penelitian selanjutnya agar meneliti pengaruh GSCM terhadap kinerja lingkungan secara kuantitatif dan bagi perusahaan agar memanfaatkan informasi pengungkapan aktivitas perusahaan dalam kelompok GSCM untuk melakukan upaya yang sama ataupun pengambilan keputusan. 


\section{Daftar Pustaka}

Beyene, Zellalem Tadesse. 2015.

"Green Supply Chain

Management Pratices In

Ethiopian Tannery Industry: An Empirical Study". International Research Journal of Engineering and Technology. Volume 2 Nomor 7.Oktober 2015. Ethiopia: St. Mary's University.

Butler, Janet B, et al. (2011). Sustainability and The Balance Scorecard: Integrating Green Measures Into Business Reporting. Jurnal Management Accounting Quarterly, Vol. 12, No 2.

Bourdeau. (2004). The Man - Nature Relationship and Environmental Ethics. Journal of Environmental Radioactivity72, pp. 9-15.

Deegan, C. (2002a). The Legitimising Effect of Social and Environmental Disclosure - a Theoretical Foundation. Accounting, Auditing \& Accountability Journal, 15(3), 282-343.

Deegan, C. (2002b). Australian Financial Accounting (3 ed.). Roseville NSW: McGraw-Hill Book Co.

Dhiman, S. (2008). Product, People, Planet: The Triple Bottom Line Sustainability Imperative.
Journal Of Global Business Issues, 2(2), 51-57

Elkington, J. (1997). Cannibals With Forks - Triple Bottom Line of 21 Century Business. Stoney Creek, CT: New Society Publishers.

Fortuna, et al. 2014. "Perancangan Sistem Pengukuran Kinerja Aktivitas Green Supply Chain Management (GSCM)" (Studi Kasus: KUD “BATU” ). Jurnal Tehnik Industri,Volume 2 Nomor 3, Tahun 2014. Malang:Universitas Brawijaya.

Gunawan, Juniati. (2010). Perception of Important Information in Corporate Social Disclosures: Evidence from Indonesia. Social Responsibility Journal, Vol. 6, No. 1, pp. 62-71.

Gunawan, Juniati (2015a). Corporate Social Disclosure in Indonesia: $\quad$ Stakeholder's Influence and Motivation. Social Responsibility Journal.

Gunawan, Juniati. (2015b). Buku Panduan Laporan Keberlanjutan: Prinsip Menetukan Isi dan Kualitas. Jakarta : Mitra Wacana Media. 